\title{
Zeyuan Liu Memorial Issue
}

\author{
Guest Editors
}

Yue Chen and Jean-Charles Lamirel 